\title{
Comparing Lithium With Valproate for Clinical and Social Status of Bipolar Disorder Patients in Inter-Episode Interval: A Retrospective Comparative Study
}

\author{
Arash Mowla ${ }^{\text {a, b}, ~ S a n a z ~ B o o s t a n i ~}{ }^{a}, Z^{2}$ ahra Ehsaei ${ }^{a}$
}

\begin{abstract}
Background: Our aim was to compare the efficacy of $\mathrm{Na}$ valproate with lithium in prolonging the time to mood episode recurrence in patients suffering from bipolar disorder (BD) type 1. Patients' social and occupational functioning in the inter-episode interval was also compared.
\end{abstract}

Methods: A total of 324 patients that were admitted in our psychiatry ward with diagnosis of BD, manic phase, were surveyed for their past psychiatry history. The patients entered the study if they had adhered to their mood stabilizing medications from their past mood episode till this current mood episode. A total of 169 patients were on lithium (mean dose: $785.7 \mathrm{mg}$ ) and 155 patients were on Na valproate (mean dose: $734.3 \mathrm{mg}$ ) while admitted. The time period the patients were in the inter-episode interval was compared between the two groups. The patients' occupational and social functioning in the inter-episode interval was also compared.

Results: The inter-episode interval was 28.7 months in the patients taking lithium and 29.4 months in the patients on Na valproate. There was no significant difference in this regard between the two groups $(\mathrm{P}=0.564)$. Furthermore, rates of substance abuse $(0.561)$, divorce (0.543), suicidal attempt $(0.693)$ and unemployment $(\mathrm{P}=0.453)$ in the inter-episode interval did not differ significantly between the lithium and valproate groups.

Conclusions: $\mathrm{Na}$ valproate was demonstrated to be as effective as lithium in preventing mood episode recurrence in bipolar patients. Our patients also demonstrated comparable occupational and social status in the inter-episode interval.

Keywords: Valproate; Lithium; Bipolar disorder

Manuscript submitted July 3, 2020, accepted July 21, 2020

Published online August 12, 2020

aSubstance Abuse and Mental Health Research Center, Hafez Hospital, Shiraz University of Medical Sciences, Shiraz, Iran

${ }^{b}$ Corresponding Author: Arash Mowla, Substance Abuse and Mental Health Research Center, Hafez Hospital, Shiraz University of Medical Sciences, Shiraz, Iran.Email: mowlaar@gmail.com

doi: https://doi.org/10.14740/jnr610
Introduction

Bipolar disorder (BD) is a recurrent major psychiatry disease that causes disability worldwide and is associated with significant healthcare costs [1]. BD is associated with elevated risk of suicide attempts and deaths [2].

In the past, emphasis was placed solely on the treatment of acute episodes of BD; recently, the importance of mood recurrence prevention and inter-episode functioning has been recognized [3]. The frequent recurrences of mood episodes in BD are associated with poorer functioning, psychiatric and medical comorbidities, and increased odds of sociality, disability, unemployment, and re-hospitalization $[4,5]$.

For many years, lithium was the only mood stabilizer in common use, and it remains an agent of first choice in treatment of manic phase of BD [6]. Valproate is an anticonvulsant drug whose efficacy in treatment of acute mania in BD has been also shown [6]. In several meta-analyses of trials of individual drugs versus placebo in treatment of mania, efficacy measures were similar for lithium and valproate and did not indicate clear superiority of one agent over the other [7-9].

In studies of mood recurrence prevention in BD patients, the long-term efficacy of lithium and valproate in preventing depressive or manic/mixed relapses has been shown in several studies [10-12]. Pharmacological treatments during bipolar maintenance should prevent manic and depressive relapse, reduce residual symptoms, suicidal risk, cycling frequency, and mood instability, and improve functioning [13].

Our objective in this survey is to compare $\mathrm{Na}$ valproate with lithium in regard with prolonging inter-episode interval in BD type 1. Also this study would compare valproate with lithium in the inter-episode phase of BD patients regarding: 1) Enhancing patients' functioning; 2) Preventing substance abuse; 3) Preventing suicide attempts; 4) Preserving marital stability; and 5) Reported adverse effects and medication satisfaction.

\section{Patients and Methods}

\section{Patients}

Our survey is a retrospective comparative study. The hos- 
Table 1. The Patients' Clinical and Demographic Status

\begin{tabular}{llll} 
& Lithium group & Valproate group & P value \\
\hline Age (mean year) & 33.51 & 32.34 & 0.473 \\
Sex (women \%) & 52 & 49 & 0.321 \\
Education (years) & 12.7 & 11.9 & 0.398 \\
Positive FHx for BD (\%) & 38.4 & 36.9 & 0.543 \\
Mood episode on admission & Mania & Mania & 0.651 \\
Previous hospital admissions (N) & 2.2 & 1.9 & \\
\hline
\end{tabular}

FHx: family history; BD: bipolar disorder; N: number.

pital charts of all the patients with diagnosis of BD type 1 (manic type) that were admitted in our psychiatry ward from June 2011 to June 2016 were reviewed. A patient's hospital chart was selected for study based on the following criteria: diagnosis of $\mathrm{BD}$ type 1, manic episode, on admission by a board certified psychiatrist according to the Diagnostic and Statistical Manual of Mental Disorders, fourth edition, text revision (DSM-IV-TR) criteria; age between 18 to 65 ; and treatment adherence to $\mathrm{Na}$ valproate or lithium in their recent inter-episode interval. Treatment adherence was evaluated by both patients and care givers' reporting. Exclusion criteria were: taking other medications or psychology interventions during inter-episode interval, having medical problems, substance abuse before the recent inter-episode interval and being mentally retarded. Of 483 charts that were reviewed, 369 met our study criteria. Necessary information for our survey could be obtained only from 324 charts (169 patients in the lithium group and 155 patients in the $\mathrm{Na}$ valproate group). The mean dosage of lithium was $785.7 \mathrm{mg}$ and the mean dosage of valproate was $734.3 \mathrm{mg}$ during the recent inter-episode interval.

\section{Assessments}

Information regarding the time in remission, employment status, marital stability, substance abuse, suicidal attempt and satisfaction about the administered mood stabilizer was gathered from the patients' hospital charts. If there was missing information in the charts, we tried to collect that by asking directly from the patients or their families.

The patients were monitored for mood symptoms in the interval between their past mood episode till their current mania recurrence by their psychiatrists. Inter-episode interval was measured by the time the patients were reported to be stable by their psychiatrists following them in the inter-episode interval. Employment status was assessed by the number of months being at work. Marital stability in each group was measured by the number of divorces in that group. Substance abuse in the groups was evaluated by the number of patients that had started substance abuse. The patients were not abusing any substance before the recent inter-episode interval. Patients' satisfaction about mood stabilizer and adverse effects were evaluated by special questions from the patients. The number of the patients that reported satisfaction with their mood stabilizer was com- pared between the two groups.

\section{Statistical analysis}

Necessary information was collected from the patients' charts or directly asking the patients and their care givers. Obtained data were statistically analyzed with IBM SPSS Statistics 21.0 for Windows (IBM Corp., Armonk, NY, USA). Chi-square and independent $t$-tests were used, as appropriate, to compare the demographic and clinical characteristics of the two groups. $\mathrm{P}$ values less than 0.05 were considered as statistically significant.

The study was approved by the ethics committee of Shiraz University of Medical Sciences that adheres to the Declaration of Helsinki Ethical Principles for Medical Research, 1964.

\section{Results}

Our retrospective study surveyed the past psychiatry history of BD patients that were admitted in Ebnesina Hospital from June 2011 to June 2016. The patients' demographic and clinical data at baseline are depicted in Table 1. The two groups did not differ significantly in regard with age, sex, education, family history of BD and pervious hospital admissions.

The mean time of remission period in lithium and $\mathrm{Na}$ valproate groups were 28.7 and 29.4 months, respectively. Indeed, our study showed that lithium or $\mathrm{Na}$ valproate did not differ significantly in prolonging the time to mood episode recurrence $(\mathrm{P}=0.564)$.

Table 2 demonstrates the patient's clinical and social status in their recent inter-episode interval. The patient's employment status (number of months being employed) did not differ significantly $(\mathrm{P}=0.453)$ between the two groups. The number of patients that had started any substance during the recent inter-episode interval did not differ significantly between the groups $(\mathrm{P}=0.561)$ as well.

The adverse events mainly reported by patients taking lithium were dizziness, dysphoria, memory problem and sleepiness. In the other group the patients complained more about drowsiness, sleepiness, tremor and weight gain. The number of the patients in the lithium and valproate groups that reported satisfaction with their mood stabilizers did not differ signifi- 
Table 2. Patients' Inter-Episode Status

\begin{tabular}{llll} 
& Lithium group & Valproate group & Statistics (P value) \\
\hline Inter-episode duration (months) & 28.7 & 29.4 & 0.564 \\
Unemployment (months) & 10.7 & 11.4 & 0.453 \\
Substance abuse, N (\%) & $25(14.7)$ & $20(12.9)$ & 0.561 \\
Patients' satisfaction with medication (\%) & 74.5 & 72.9 & 0.632 \\
Divorce, N (\%) & $44(25.8)$ & $42(27.1)$ & 0.543 \\
Suicide attempt, N (\%) & $15(8.8)$ & $14(9.03)$ & 0.693 \\
\hline
\end{tabular}

$\mathrm{N}$ : number.

cantly between the two groups $(\mathrm{P}=0.632)$.

\section{Discussion}

Our retrospective study showed that $\mathrm{Na}$ valproate is as effective as lithium in prolonging the time to mood episode recurrence. It also demonstrated that rates of unemployment, divorce, substance abuse and suicidal attempt were not significantly different between the groups in the inter-episode interval. Patients of the two groups also had similar rate of satisfaction about their medication.

For many years, lithium was the only mood stabilizer in common use, and it remains an agent of first choice in the treatment of acute mania and maintenance of BD [6]. Moreover, several studies have revealed the efficacy of valproate in both treating mania and preventing mood episodes in BD patients [14-16]. Several studies have compared valproate with lithium for both acute and maintenance phases of BD. In a randomized double-blind controlled trial of lithium and divalproex in the treatment of mania in patients with $\mathrm{BD}$, both lithium and divalproex were adequately tolerated and efficacious [17]. In another trial comparing divalproax with lithium for initial treatment of mania in adolescent patients, both treatments had comparable results [18]. A systemic review of pharmacological treatments in maintenance phase of BD patients revealed efficacy for both valproate and lithium [15]. However, in a long-term maintenance therapy of BD patients, divalproex was superior to lithium in longer duration of successful prophylaxis in the study and less deterioration in depressive symptoms and Global Assessment Scale scores [19]. Our study revealed that $\mathrm{Na}$ valproate was as effective as lithium in preventing mood episode recurrence.

Patients suffering from BD are at elevated risk of suicide attempts and suicide [20-22]. The extensive literature on the impact of lithium use on both suicide attempts and suicide deaths in BD samples demonstrated that lithium was significantly associated with a reduced risk of suicide compared to placebo [23, 24]. Nonetheless, several studies have found higher rates of suicidal events in patients on valproate compared to lithium $[25,26]$. However, there are surveys that have failed to find differences in suicidal behavior between valproate and lithium $[27,28]$. Our research did not find any significant difference between lithium and valproate groups regarding suicidal behavior.
Patients with BD frequently report co-occurring substance use disorders more than that in the general population [29]. A current or past comorbid substance use disorder may lead to worse outcomes for BD, including more symptoms, more suicide attempts, longer episodes, greater treatment non-adherence and lower quality of life [30-32]. Other studies have reported better functioning and quality of life and less suicidal attempts in bipolar patients without history of substance abuse compared to those with current or past history of substance abuse $[33,34]$. Valproate has shown efficacy in reducing alcohol consumption in patients with BD and comorbid alcohol dependency in one study [35]. Evidence from several studies suggests the rate of substance abuse in rapid cycling bipolar patients to be about $40 \%[36,37]$. Our study reveals the rate of substance abuse in the lithium and valproate groups to be $14.3 \%$ and $12.9 \%$, respectively. Our study shows that the rate of substance abuse by our patients in both lithium and valproate groups did not differ significantly.

There are researches indicating that there are high rates of divorce and volatility in marital relationships of patients with BD. Care-giving burden and psychological distress among spouses of patients with $\mathrm{BD}$ have been reported to be high $[38,39]$. Therefore, studies on BD patients need to survey all aspects of their social life. Two previous studies had reported the rate of divorce in bipolar patients to be $24 \%$ and $28 \%$ respectively [40, 41]. Our study showed that about $25.7 \%$ of marriage of BD patients on lithium and $27.1 \%$ of marriage of $\mathrm{BD}$ patients on valproate had led to divorce. There were no significant differences in this regard between the two groups.

Our study is a retrospective survey. Most of our information was gathered from the patients' hospital charts. Clinical trials are needed to better compare lithium and valproate for their efficacy in preventing mood episode recurrence. Patient's occupational and social functioning in the inter-episode intervals also can be monitored and surveyed more precisely in prospective studies.

\section{Conclusions}

Our study showed that valproate is as effective as lithium in preventing mood episode recurrence in bipolar disorder. Furthermore, patients taking $\mathrm{Na}$ valproate and lithium did not reveal significant difference regarding occupational functioning, rate of divorce, substance abuse, suicidal attempt and medica- 
tion intolerability in inter-episode interval.

\section{Acknowledgments}

None to declare.

\section{Financial Disclosure}

This study was funded by vice chancellor for research of Shiraz University of Medical Sciences with grant number 95-0134-13094.

\section{Conflict of Interest}

None to declare.

\section{Informed Consent}

All patients provided written informed consent to participate in the study.

\section{Author Contributions}

All the authors were involved in designing the method of this research and contributed to carrying it out. AM wrote the paper and submitted it to the journal.

\section{Data Availability}

The authors declare that data supporting the findings of this study are available within the article.

\section{References}

1. Cerimele JM, Chwastiak LA, Chan YF, Harrison DA, Unutzer J. The presentation, recognition and management of bipolar depression in primary care. J Gen Intern Med. 2013;28(12):1648-1656.

2. Wingo AP, Baldessarini RJ, Compton MT, Harvey PD. Correlates of recovery of social functioning in types I and II bipolar disorder patients. Psychiatry Res. 2010;177(12):131-134.

3. Harrison PJ, Cipriani A, Harmer CJ, Nobre AC, Saunders $\mathrm{K}$, Goodwin GM, Geddes JR. Innovative approaches to bipolar disorder and its treatment. Ann N Y Acad Sci. 2016;1366(1):76-89.

4. Schaffer A, Isometsa ET, Tondo L, Moreno DH, Sinyor M, Kessing LV, Turecki G, et al. Epidemiology, neurobiology and pharmacological interventions related to suicide deaths and suicide attempts in bipolar disorder: Part I of a report of the International Society for Bipo- lar Disorders Task Force on Suicide in Bipolar Disorder. Aust N Z J Psychiatry. 2015;49(9):785-802.

5. Peters AT, West AE, Eisner L, Baek J, Deckersbach T. The burden of repeated mood episodes in bipolar I disorder: results from the national epidemiological survey on alcohol and related conditions. J Nerv Ment Dis. 2016;204(2):87-94.

6. Goodwin GM, Haddad PM, Ferrier IN, Aronson JK, Barnes T, Cipriani A, Coghill DR, et al. Evidencebased guidelines for treating bipolar disorder: Revised third edition recommendations from the British Association for Psychopharmacology. J Psychopharmacol. 2016;30(6):495-553.

7. Fountoulakis KN, Yatham L, Grunze H, Vieta E, Young A, Blier P, Kasper S, et al. The International College of Neuro-Psychopharmacology (CINP) treatment guidelines for bipolar disorder in adults (CINP-BD-2017), part 2: review, grading of the evidence, and a precise algorithm. Int J Neuropsychopharmacol. 2017;20(2):121-179.

8. Yildiz A, Vieta E, Leucht S, Baldessarini RJ. Efficacy of antimanic treatments: meta-analysis of randomized, controlled trials. Neuropsychopharmacology. 2011;36(2):375-389.

9. Bowden CL, Brugger AM, Swann AC, Calabrese JR, Janicak PG, Petty F, Dilsaver SC, et al. Efficacy of divalproex vs lithium and placebo in the treatment of mania. The Depakote Mania Study Group. JAMA. 1994;271(12):918924.

10. Jeong JH, Lee JG, Kim MD, Sohn I, Shim SH, Wang HR, Woo YS, et al. Korean Medication Algorithm for Bipolar Disorder 2014: comparisons with other treatment guidelines. Neuropsychiatr Dis Treat. 2015;11:1561-1571.

11. Yatham LN, Kennedy SH, Parikh SV, Schaffer A, Beaulieu S, Alda M, O'Donovan C, et al. Canadian Network for Mood and Anxiety Treatments (CANMAT) and International Society for Bipolar Disorders (ISBD) collaborative update of CANMAT guidelines for the management of patients with bipolar disorder: update 2013. Bipolar Disord. $2013 ; 15(1): 1-44$.

12. Vieta E, Gunther O, Locklear J, Ekman M, Miltenburger C, Chatterton ML, Astrom M, et al. Effectiveness of psychotropic medications in the maintenance phase of bipolar disorder: a meta-analysis of randomized controlled trials. Int J Neuropsychopharmacol. 2011;14(8):1029-1049.

13. Muneer A. Pharmacotherapy of bipolar disorder with quetiapine: a recent literature review and an update. Clin Psychopharmacol Neurosci. 2015;13(1):25-35.

14. Macritchie K, Geddes JR, Scott J, Haslam D, de Lima M, Goodwin G. Valproate for acute mood episodes in bipolar disorder. Cochrane Database Syst Rev. 2003;1:CD004052.

15. Miura T, Noma H, Furukawa TA, Mitsuyasu H, Tanaka S, Stockton S, Salanti G, et al. Comparative efficacy and tolerability of pharmacological treatments in the maintenance treatment of bipolar disorder: a systematic review and network meta-analysis. Lancet Psychiatry. 2014;1(5):351-359.

16. Cipriani A, Reid K, Young AH, Macritchie K, Geddes J. Valproic acid, valproate and divalproex in the maintenance treatment of bipolar disorder. Cochrane Database 
Syst Rev. 2013;10:CD003196.

17. Young RC, Mulsant BH, Sajatovic M, Gildengers AG, Gyulai L, Al Jurdi RK, Beyer J, et al. GERI-BD: a randomized double-blind controlled trial of lithium and divalproex in the treatment of mania in older patients with bipolar disorder. Am J Psychiatry. 2017;174(11):10861093.

18. Geller B, Luby JL, Joshi P, Wagner KD, Emslie G, Walkup JT, Axelson DA, et al. A randomized controlled trial of risperidone, lithium, or divalproex sodium for initial treatment of bipolar I disorder, manic or mixed phase, in children and adolescents. Arch Gen Psychiatry. 2012;69(5):515-528.

19. Bowden CL, Calabrese JR, McElroy SL, Gyulai L, Wassef A, Petty F, Pope HG, Jr., et al. A randomized, placebo-controlled 12-month trial of divalproex and lithium in treatment of outpatients with bipolar I disorder. Divalproex Maintenance Study Group. Arch Gen Psychiatry. 2000;57(5):481-489.

20. Crump C, Sundquist K, Winkleby MA, Sundquist J. Comorbidities and mortality in bipolar disorder: a Swedish national cohort study. JAMA Psychiatry. 2013;70(9):931939.

21. Dennehy EB, Marangell LB, Allen MH, Chessick C, Wisniewski SR, Thase ME. Suicide and suicide attempts in the Systematic Treatment Enhancement Program for Bipolar Disorder (STEP-BD). J Affect Disord. 2011;133(3):423427.

22. Singhal A, Ross J, Seminog O, Hawton K, Goldacre MJ. Risk of self-harm and suicide in people with specific psychiatric and physical disorders: comparisons between disorders using English national record linkage. J R Soc Med. 2014;107(5):194-204.

23. Baldessarini RJ, Tondo L. Lithium and suicidal risk. Bipolar Disord. 2008;10(1):114-115.

24. Cipriani A, Hawton K, Stockton S, Geddes JR. Lithium in the prevention of suicide in mood disorders: updated systematic review and meta-analysis. BMJ. 2013;346:f3646.

25. Baldessarini RJ, Tondo L. Suicidal risks during treatment of bipolar disorder patients with lithium versus anticonvulsants. Pharmacopsychiatry. 2009;42(2):72-75.

26. Goodwin FK, Fireman B, Simon GE, Hunkeler EM, Lee J, Revicki D. Suicide risk in bipolar disorder during treatment with lithium and divalproex. JAMA. 2003;290(11):1467-1473.

27. Oquendo MA, Galfalvy HC, Currier D, Grunebaum MF, Sher L, Sullivan GM, Burke AK, et al. Treatment of suicide attempters with bipolar disorder: a randomized clinical trial comparing lithium and valproate in the prevention of suicidal behavior. Am J Psychiatry. 2011;168(10):1050-1056.

28. Yerevanian BI, Koek RJ, Mintz J. Lithium, anticonvulsants and suicidal behavior in bipolar disorder. J Affect
Disord. 2003;73(3):223-228.

29. Vornik LA, Brown ES. Management of comorbid bipolar disorder and substance abuse. J Clin Psychiatry. 2006;67(Suppl 7):24-30.

30. Ostacher MJ, Sachs GS. Update on bipolar disorder and substance abuse: recent findings and treatment strategies. J Clin Psychiatry. 2006;67(9):e10.

31. Sajatovic M, Valenstein M, Blow FC, Ganoczy D, Ignacio RV. Treatment adherence with antipsychotic medications in bipolar disorder. Bipolar Disord. 2006;8(3):232241.

32. Cassidy F, Ahearn EP, Carroll BJ. Substance abuse in bipolar disorder. Bipolar Disord. 2001;3(4):181-188.

33. Weiss RD, Ostacher MJ, Otto MW, Calabrese JR, Fossey M, Wisniewski SR, Bowden CL, et al. Does recovery from substance use disorder matter in patients with bipolar disorder? J Clin Psychiatry. 2005;66(6):730-735; quiz 808-739.

34. Brown ES. Management of comorbid bipolar disorder and substance abuse. J Clin Psychiatry. 2006;67(8):e05.

35. Salloum IM, Cornelius JR, Daley DC, Kirisci L, Himmelhoch JM, Thase ME. Efficacy of valproate maintenance in patients with bipolar disorder and alcoholism: a double-blind placebo-controlled study. Arch Gen Psychiatry. 2005;62(1):37-45.

36. Schneck CD, Miklowitz DJ, Calabrese JR, Allen MH, Thomas MR, Wisniewski SR, Miyahara S, et al. Phenomenology of rapid-cycling bipolar disorder: data from the first 500 participants in the Systematic Treatment Enhancement Program. Am J Psychiatry. 2004;161(10):19021908.

37. Kemp DE, Gao K, Ganocy SJ, Elhaj O, Bilali SR, Conroy C, Findling RL, et al. A 6-month, double-blind, maintenance trial of lithium monotherapy versus the combination of lithium and divalproex for rapid-cycling bipolar disorder and Co-occurring substance abuse or dependence. J Clin Psychiatry. 2009;70(1):113-121.

38. Arciszewska AI, Siwek M, Dudek D. Caregiving burden and psychological distress among spouses of bipolar patients - comparative analysis of subtype I and II. Psychiatr Pol. 2015;49(6):1289-1302.

39. Beentjes TA, Goossens PJ, Poslawsky IE. Caregiver burden in bipolar hypomania and mania: a systematic review. Perspect Psychiatr Care. 2012;48(4):187-197.

40. Suppes T, Leverich GS, Keck PE, Nolen WA, Denicoff KD, Altshuler LL, McElroy SL, et al. The Stanley Foundation Bipolar Treatment Outcome Network. II. Demographics and illness characteristics of the first $261 \mathrm{pa}-$ tients. J Affect Disord. 2001;67(1-3):45-59.

41. Lish JD, Dime-Meenan S, Whybrow PC, Price RA, Hirschfeld RM. The National Depressive and Manicdepressive Association (DMDA) survey of bipolar members. J Affect Disord. 1994;31(4):281-294. 